\title{
Numerical Investigation of the Effect of Rolling on the Localized Stress and Strain Induction for Wire + Arc Additive Manufactured Structures
}

\author{
M. Abbaszadeh, J.R. Hönnige, F. Martina, L. Neto, N. Kashaev, P. Colegrove, S. Williams, and B. Klusemann
}

(Submitted January 30, 2019; in revised form June 28, 2019; published online August 16, 2019)

\begin{abstract}
Cold rolling can be used in-process or post-process to improve microstructure, mechanical properties and residual stress in directed-energy-deposition techniques, such as the high deposition rate wire + arc additive manufacturing (WAAM) process. Finite element simulations of the rolling process are employed to investigate the effect of rolling parameters, in particular rolling load and roller profile radius on the residual stress field as well as plastic strain distribution for the profiled roller. The results show the response to rolling of commonly used structural metals in WAAM, i.e., AA2319, S335JR steel and Ti-6Al-4V, taking into account the presence of residual stresses. The rolling load leads to changes in the location and the maximum value of the compressive residual stresses, as well as the depth of the compressive residual stresses. However, the roller profile radius only changes the maximum value of these compressive residual stresses. Changing the rolling load influences the equivalent plastic strain close to the top surface of the wall as well as in deeper areas, whereas the influence of the roller profile radius is negligible. The plastic strain distribution is virtually unaffected by the initial residual stresses prior to rolling. Finally, design curves were generated from the simulations for different materials, suggesting ideal rolling load and roller profile combinations for microstructural improvement requiring certain plastic strains at a specific depth of the additive structure.
\end{abstract}

Keywords AA2319, cold working, design curve, finite element method, profiled rolling, S355JR, Ti-6Al-4V

\section{Introduction}

Wire + arc additive manufacturing (WAAM) uses arc power heat sources to deposit metal wire for the production of medium-complexity near-net-shape freeform components for large-scale structural applications. Typical materials for WAAM are structural metals, such as titanium, aluminum, steel or Inconel $^{\circledR}$ (Ref 1, 2). Using the WAMM process, a large additive subtractive integrated modular machine (LASIMM) is currently being developed in the European project LASIMM (Ref 3). The modular hybrid machine developed within the LASIMM project offers the possibility to employ in situ and postprocessing techniques such as milling and rolling in a single setup. Two of the main challenges in WAAM are (1) residual

\footnotetext{
M. Abbaszadeh and N. Kashaev, Institute of Materials Research, Materials Mechanics, Helmholtz-Zentrum Geesthacht, Max-PlanckStraße 1, 21502 Geesthacht, Germany; J.R. Hönnige, F. Martina, L. Neto, and S. Williams, Welding Engineering and Laser Processing Centre, Cranfield University, Cranfield MK43 0AL, UK; P. Colegrove, AML3D Technologies, 14 Pentland Road, Salisbury South 5106, Australia; and B. Klusemann, Institute of Materials Research, Materials Mechanics, Helmholtz-Zentrum Geesthacht, Max-PlanckStraße 1, 21502 Geesthacht, Germany; and Institute of Product and Process Innovation, Leuphana University of Lüneburg, Universitätsallee 1, 21335 Lüneburg, Germany. Contact e-mail: masoud.abbaszadeh@hzg.de.
}

stresses and (2) disadvantageous microstructures, resulting in mechanical properties that can be lower than the equivalent wrought alloys and/or anisotropic (Ref 1,2). These challenges arise from the process-specific thermal history and the thermomechanical material characteristics.

The mechanism of residual stress development in WAAM and the consequences are similar for different metals. Constrained thermal contraction after the deposition develops large tensile residual stresses in longitudinal direction. These stresses can cause severe distortion ( $\operatorname{Ref} 1,2,4)$ and/or premature failure during deposition or service life (Ref 5). In aluminum and steel deposits, for example, these stresses are usually close to the materials as-deposited yield strength (Ref 6-8). The largest absolute residual stresses and associated distortion in WAAM can be observed in titanium deposits (Ref 9-12).

In contrast to the residual stresses, microstructural development and the effect on mechanical performance of the three aforementioned materials are different. In WAAM Ti-6Al-4V, large columnar $\beta$ grains are developed that can grow through the entire height of the component (Ref 13). They pass on their strong texture to the room temperature $\alpha$-lamellae during phase transformation, as described in detail by Donoghue et al. (Ref 14). Low-carbon steel deposits typically consist of alternating regions of refined and non-refined layers of ferrite. Refinement of this material is produced when the material is heated above the austenitization temperature during the subsequent deposition of further layers, as identified by Colegrove et al. (Ref 8). According to $\mathrm{Gu}$ et al. (Ref 15, 16), the biggest microstructural challenge in aluminum deposits are hydrogen gas pores, which also grow larger during the subsequent heat treatment and aging. Overall, such effects lead usually to reduced strength, ductility and fracture toughness, as well as anisotropic properties in all three materials. 
Bulk deformation techniques, such as rolling, can be used as inter-pass or as a post-process to improve both, residual stresses and the microstructure (Ref $1,6,8,12,17)$. Vertical rolling was successfully used to induce significant plastic strain into the top region of titanium, steel and aluminum walls (Ref $6,8,14$ ). When applied inter-pass rolling to titanium, the heat of the subsequent deposition improves the grain morphology of the plastically strained material, refining it to equiaxed grains with reduced texture. Moreover, porosity in aluminum deposits can be fully eliminated, to the point that it does not even reappear during heat treatment. The detailed mechanism of microstructural improvement in inter-pass rolling for each material, as well as the effect on the mechanical properties, is described elsewhere [steel (Ref 8), Ti-6Al-4V (Ref 14) and aluminum (Ref 15, 16)]. The required plastic strain is estimated to be $>10 \%(\operatorname{Ref} 14)$ and $>30 \%(\operatorname{Ref} 8)$ to refine the Ti-6Al-4V and steel AM microstructure, respectively, by subsequent thermal processing and $>40 \%$ (Ref 15$)$ to eliminate porosity in aluminum deposits.

Vertical rolling also reduces residual stress and distortion (Ref 8$10)$ and in the case of aluminum (Ref 6 ) also eliminates distortion. However, rolling is much more effective when the material is strained longitudinally, while preventing transverse deformation (Ref 6,9). It should be noted that the main purpose of rolling is the microstructural improvement, but the beneficial effect on the residual stress is significant as well. However, a direct elimination of residual stress is not critical for practical applications, as relatively inexpensive heat treatments can be applied to the near-net-shape component before finish machining to increase the materials strength and/or to guarantee a complete stress-free part.

Overall, the measurement of residual stresses in WAAM structures is cumbersome, very time-consuming or lacks the required resolution. The quantitative measurement of plastic strains is virtually impossible. Furthermore, the ideal rolling load to achieve certain plastic strains in desired regions, for a given geometry of the roller, is mostly unknown or requires extensive experimental effort. Therefore, numerical approaches can provide further insight on how rolling can be used efficiently to reduce residual stresses and provide the required plastic strains for microstructural improvement, as mentioned above. In this paper, the FEM method is employed to investigate the effect of different rolling process parameters, such as rolling load and roller profile radius, on the residual stress and plastic strain distribution in three different materials, AA2319, S355JR steel and Ti-6Al-4V, all deposited by WAAM. To avoid simulating the full WAAM process, including the full deposition process, the initial stress approach (Ref 18 ) is applied to allocate the as-clamped residual stresses derived experimentally from WAAM process (Ref 6, 9) or actual WAAM simulation (Ref 4) in the model. The rolling process is systematically investigated via FEM, and design curves are obtained. The main practical benefit of such design curves is the ability to select roller profile radius and rolling load based on the desired plastic strain condition, thus minimizing long experiment-based investigations.

\section{Numerical Methodology}

Rolling of WAAM walls was simulated using the finite element method (FEM) software ABAQUS/Standard. All specimens of the three materials, Ti-6Al-4V, S355JR steel and AA2319, were simulated with identical dimensions. The $80 \times 6 \times 24 \mathrm{~mm}^{3}$ walls were placed in the center of a $100 \times 32.5 \times 6.35 \mathrm{~mm}^{3}$ substrate and perfectly connected to the substrate plate. This wall geometry represents experimentally 20 layers using plasma transferred arc (PTA) power source for Ti-6Al-4V (Ref 10) and 12 and 10 layers using gas metal arc welding (GMAW) power sources for S355JR steel (Ref 8) and AA2319 (Ref 15), respectively. By applying symmetry boundary conditions at the symmetry plane, as shown in Fig. 1, the computational costs are reduced. Preliminary simulations with larger specimen dimensions showed the equivalent results in terms of plastic strains and residual stresses, indicating a sufficiently large size of the substrate and wall. The shape of the top layer was modeled as a semicircle based on experimental observations (Ref 19), see Fig. 1. 8-node linear hexahedral elements with reduced integration (C3D8R) are used to discretize the model. A fine mesh was used in the area where large deformation is obtained due to the rolling process. The dimensions of elements in the deformation zone near the top surface of the wall were $500 \mu \mathrm{m}$ in $x$ - and $50 \mu \mathrm{m}$ in $y$ - and $z$ direction. The rolled longitudinal distance ("travel distance") represents the minimum length at which all simulations reached a steady state. Consequently, a longer rolling distance would not lead to additional insight. A coarse mesh in the area further away from the deformation zone does not influence the result, as also shown in Ref 20.

For all three materials, a linear elastic-plastic material behavior is considered based on experimental data obtained from compression tests. Cylindrical samples with length and diameter of $15 \mathrm{~mm}$ and $10 \mathrm{~mm}$, respectively, were cut from the building direction (z-direction) of corresponding WAAM samples. A SCHENCK servo-hydraulic 1000-kN machine was used to perform the compression tests. The lateral and transversal deformation of the specimen was measured with two sets of laser extensometers. The values of Young's modulus reported in Table 1 are taken from experimental tensile tests from Ref 21-23 for AA2319, S355JR steel and Ti-6Al-4V, respectively. The plastic behavior of all three materials, obtained from compression tests in the vertical direction of WAAM specimens, is provided in Fig. 2. To avoid modeling failure explicitly, the material behavior is assumed as ideal plastic after the experimental failure point. For simplicity, it is assumed that the material can be treated as isotropic in the modeling of the rolling process where the relevant properties are determined by those in vertical direction. Further details about the (anisotropic) mechanical behavior and microstructure will be reported in the future. As discussed previously, although rolling leads to microstructural changes, which in turn affects the mechanical properties, such changes are neglected in the current modeling approach. The effect of this assumption on the resulting strain distribution, relevant to initiate microstructure refinement, is expected to be negligible but has of course always to be considered in the interpretation and application of the obtained simulation results. It should also be mentioned that a sensitivity study using tensile test data available in the literature Ref 21-23 was carried out and was found to not affect the modeling results significantly.

The simulation procedure consisted of two steps: (1) introduction of as-clamped stresses to the model via the "initial stress" approach and (2) modeling the rolling process. Each step is described in the following sections. 


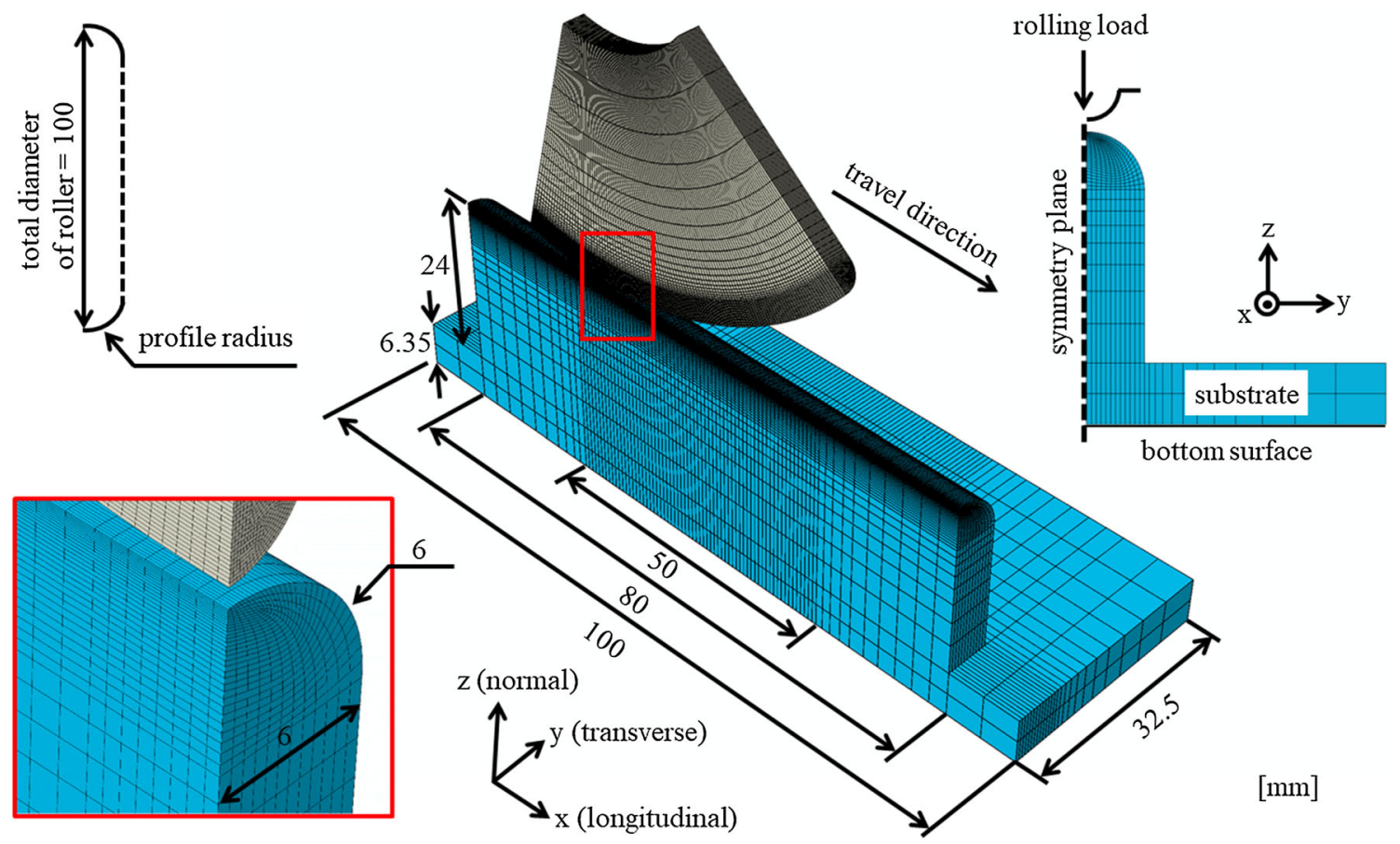

Fig. 1 Finite element model of the specimen and roller (dimensions in $\mathrm{mm}$ ) using symmetry conditions to reduce the model size. Furthermore, the length of the wall was reduced compared to actual experiments based on the assumption that the stresses in the center of the wall are not influenced by edge effects due to run-in and run-out step. The relevant part of the roller is located on top of the WAAM structure

Table 1 Young's modulus and yield strength of AA2319, S355JR steel and Ti-6Al-4V. Young's modulus for AA2319, S355JR steel and Ti-6Al-4V were taken from tensile stress-strain curve from (Ref 21-23), respectively. The values of yield strength were approximated from the experimental compressive tests, see Fig. 2

\begin{tabular}{llcr}
\hline & Poisson ratio & Young's modulus, GPa & Compressive yield strength, MPa \\
\hline AA2319 & $0.33($ Ref 24$)$ & $70(\operatorname{Ref} 21)$ & 120 \\
S355JR steel & $0.3(\operatorname{Ref} 25)$ & $200(\operatorname{Ref} 22)$ & 365 \\
Ti-6A1-4V & $0.342(\operatorname{Ref} 26)$ & $113(\operatorname{Ref} 23)$ & 950 \\
\hline
\end{tabular}

\subsection{Introduction of As-Clamped Stresses into the Model}

Instead of performing time-consuming simulations of the actual WAAM process (Ref 27-30) to incorporate the initial residual stresses in the structure, appropriate effective methods such as "eigenstrain" (Ref 31, 32) or "initial stress" (Ref 18) approaches can be used. For instance, it was previously reported that the simulation of the actual WAAM process can take up to $15 \mathrm{~h}$ for 4 layers ( $\operatorname{Ref} 4,7$ ). In the eigenstrain approach, a distribution of thermal expansion coefficients, corresponding to desired eigenstrains, is prescribed across the model to reach the required elastic strains that lead to the targeted residual stresses (Ref 33,34 ). In addition, an uniform temperature rise needs to be introduced to the whole model. In contrast, the "initial stress" approach accounts for the final asclamped stress distribution, obtained, e.g., from experiment or previous finite element simulations, by incorporating an initial stress distribution in the FE model, where the iterative adjustment to the final target stress distribution requires several elastic FE calculations. The "initial stress" method was initially proposed by Lei et al. (Ref 18) for fracture mechanics analysis of cracks. This approach works by introducing initial stresses as initial conditions. However, these introduced initial stresses do not fulfill equilibrium. Therefore, the equilibrium of the introduced initial stresses has to be calculated subsequently. The stress distribution of the resulting equilibrium leads to redistributed stresses within the structure, representing the actual residual stresses present in the structure. The initial stresses need to be varied iteratively based on the redistributed stresses until the desired residual stresses are obtained. Proportional integral adjustment (Ref 18) is used to modify the initial values to reproduce the desired values in the finite element model as follows:

$\sigma_{x x}(y)_{\text {inp }}^{i+1}=\sigma_{x x}(y)_{\text {inp }}^{i}+\alpha\left[\sigma_{x x}(y)_{\operatorname{targ}}-\sigma_{x x}(y)_{\text {out }}^{i}\right]$.

Here, $\sigma_{x x}(y)_{\text {inp }}^{i}$ and $\sigma_{x x}(y)_{\text {inp }}^{i+1}$ are the initial stresses incorporated into the model in the $i$ th and $(i+1)$ th iteration, respectively. $\sigma_{x x}(y)_{\text {out }}^{i}$ represents the resulting stress distribution due to $\sigma_{x x}(y)_{\text {inp }}^{i}$ after reaching equilibrium. $\sigma_{x x}(y)_{\operatorname{targ}}$ is the target residual stress distribution which corresponds to experimentally measured residual stresses in WAAM structures. The assigned residual stress values in the simulation change only along the $z$-direction and are assumed constant in the $x-y$ plane, as noted in Ref 35 . $\alpha$ denotes the integral factor which is considered as one here for simplicity. During the simulation based on the initial stress approach, the bottom surface of the substrate is fixed for all displacement and rotational degrees of 


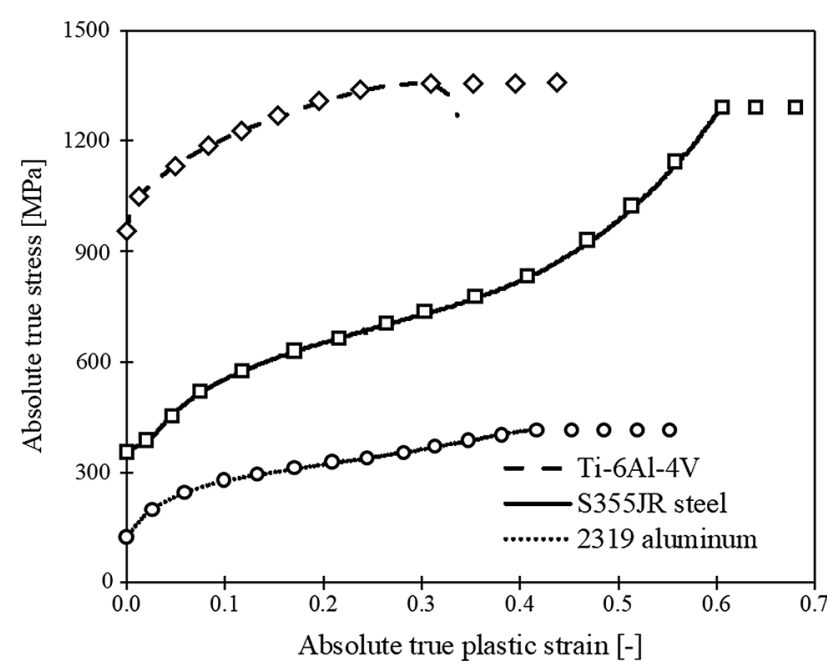

Fig. 2 Experimentally determined compressive true stress-true plastic strain curves of WAAM deposited Ti-6Al-4V, S355JR steel and AA2319, obtained for the vertical loading direction. Markers represent the material data used in the simulation, where an ideal plastic behavior is considered after the experimental failure points

freedom. Based on experimentally reported residual stress data of WAAM structures, the average values of the longitudinal tensile residual stresses in as-clamped state for Ti-6Al-4V, S355JR steel and AA2319 were considered as 550 (Ref 9), $330^{*}$ and $110 \mathrm{MPa}(\operatorname{Ref} 6)$, respectively.

\subsection{Finite Element Model of the Rolling Process}

The residual stresses, introduced by the "initial stress" approach, represent the initial condition of the subsequent rolling process simulation. Three ring rollers (Ref 8) with different roller profile radii $(1.5,3$ and $6 \mathrm{~mm}$ in radius) were used. The rollers were modeled as deformable bodies with a total outer diameter of $100 \mathrm{~mm}$. Perfect linear elastic material with Young's modulus of $230 \mathrm{GPa}$ ( $\operatorname{Ref} 36$ ) was considered to model the mechanical behavior of the rollers.** The rollers were discretized with 8-node linear hexahedral elements with reduced integration (C3D8R) with average element length of $500 \mu \mathrm{m}$ near the outer diameter of the roller, see Fig. 1. A surface-to-surface contact based on a finite-sliding contact formulation with a tangential friction coefficient of $\mu=0.3$ (penalty formulation) and hard normal contact conditions were assumed to define the interaction between the roller and WAAM structure. Sensitivity studies showed that the simulation results are nearly independent of the friction coefficient, meaning that there was less than $5 \%$ difference between the

\footnotetext{
*Experimentally a value of $500 \mathrm{MPa}$ is reported in Ref 4 . However, such a stress value cannot be reached if the experimentally measured yield strength is $360 \mathrm{MPa}$, as shown in Fig. 2. Therefore, it was assumed that the residual stresses in the as-clamped state of the steel wall are lower than the residual stresses reported in Ref 4 . As it was noted in this work, that the residual stresses reach approximately $90 \%$ of the yield strength, initial longitudinal residual stresses of $330 \mathrm{MPa}$ are assumed for S355JR in this work.

**From computational point of view, the rollers might be modeled as rigid body. Preliminary simulations indicated that at low deformation nearly no differences between rolling with deformable and rigid rollers is present. However, with increasing deformation, differences in terms of stress and force were detectable.
}

results for a friction coefficient of $\mu=0.3$ and 0.8. Cozzolino et al. (Ref 37) showed that the friction coefficient has negligible effect on the residual stress as the deformation achieved by rolling is comparatively low, e.g., at a rolling load of $25 \mathrm{kN}$ for S355JR steel. The rolling step consists of two substeps: (1) penetration and (2) rolling.

During both steps, the bottom surface of the substrate was constrained in all directions. During the penetration step, the roller was constrained in all translational and rotational directions except for the prescribed displacement in z-direction to reach a specific penetration depth. In the rolling step, the penetration depth was kept constant and the roller moves in $\mathrm{x}$ direction at a constant travel speed of $7 \mathrm{~mm} / \mathrm{s}$. Furthermore, the roller could rotate around the y-axis during rolling, due to friction. A displacement-controlled simulation rather than a force-controlled was chosen due to numerical reasons (Ref 38 ). In the study by Foehrenbach et al. (Ref 38), it was shown that the residual stresses simulated by a displacement-controlled simulation approach have even a closer agreement with experimental values compared to a force-controlled approach. However, if the simulation is intended to achieve a specific rolling load, the depth needs to be determined iteratively.

To use the information systematically, for a simulation based process design, design curves were determined, providing the necessary parameter combinations to obtain the required strain for microstructural modification as mentioned in the introduction. To obtain these, the resulting equivalent plastic strains were extracted at different depths in all calculations for each material. Then, a polynomial regression model of the second order was created for each depth using the function fitlm available in MATLAB programming software. This model allows to identify a relation for each material which determines the equivalent plastic strain as a function of the input parameters, i.e., rolling load and roller profile radius, at one specific depth:

$\bar{\varepsilon}^{p}=a_{1} F^{2}+a_{2} R^{2}+a_{3} F+a_{4} R+a_{5} F R+a_{6}$.

$F$ and $R$ represent the rolling load and roller profile radius, respectively, and $a_{1 \sim 6}$ are model specific coefficients which have to be determined, for instance, for each depth and material, see Table 3. The obtained regression models for each material were used to predict the equivalent plastic strain at different depths for the combinations of rolling load and roller profile radius, illustrated as design curves of the equivalent plastic strain.

\subsection{Parameter Study}

A parametric study was performed based on the setup shown in Fig. 1. Practical combinations of rolling loads and roller profiles were used, which were established in previous experimental works for the three materials, see Ref 8, 10, 12, 17, 39, 40. The minimum and maximum values for this parametric study are listed in Table 2, which were used on the different deposits.

\section{Results and Discussion}

Rolling can be used for microstructural control (Ref 12, 41) and stress mitigation independently (Ref 6,9$)$ or to improve both simultaneously ( $\operatorname{Ref} 6,8,10,15,39)$. The practical 
application for either purpose is therefore discussed separately, starting with stress modification and followed by microstructural improvement.

\subsection{The Effect of Rolling on the Residual Stress Distribution}

The side view of the contour plots of the equivalent (von Mises) stresses in the Ti-6Al-4V specimen and roller during rolling with load of $70 \mathrm{kN}$ and different roller profile radii is displayed in Fig. 3. Due to the lower yield strength of S355JR steel and AA2319 compared to Ti-6Al-4V, the stresses produced in the roller during the rolling are lower with these materials. As shown in Fig. 3, the stresses produced in the roller are decreased by increasing the roller profile radius. The reason is attributed to the larger contact area between roller and top surface of the wall for increased roller profile radius that leads to lower pressures applied to the roller. The effect of rolling load and profiles on the longitudinal residual stresses in the Ti-6Al-4V wall is shown in detail in Fig. 4. The quantitative values of the residual stresses in Fig. 4 (bottom) are obtained along the symmetry plane. For all combinations of loads and profiles, compressive stresses are induced near the top of the wall. A higher rolling load results in deeper compressive residual stress, see Fig. 4(a). However, it is also indicated that for an increase in the rolling load, tensile residual stresses are produced near the top surface of the wall due to friction. Increasing the load increases the peak compressive stress and the respective location. Figure 4(b) shows that the change in roller profile radius has a small effect on the stress profile.

Since the roller profile radius has little effect, only the rolling load with a 3-mm roller profile radius is discussed for S355JR steel and AA2319, see Fig. 5. In this figure, the longitudinal residual stress distribution at a depth of $6 \mathrm{~mm}$ along the width of the wall as well as the longitudinal residual stress in vertical direction over the height of the wall is plotted for both materials. The dashed line in the stress map in Fig. 5(b) indicates residual stresses of $0 \mathrm{MPa}$. The overall distribution of the stresses in S355JR steel and AA2319 after rolling is comparable to the Ti-6Al-4V wall; with increasing rolling load, the depth of the compressive residual stresses increases, meanwhile tensile residual stresses are generated near the top surface of the wall. This was also observed experimentally (Ref 6). Due to the lower yield strength of AA2319, larger deformations are present for same rolling load. Increasing the rolling load leads to a more beneficial stress state, with the core of the wall exhibiting tensile residual stresses, balanced by compressive stress at the surface. Such surface compressive stresses are otherwise induced with big effort on DED components, for instance, by laser shock peening, to improve tensile strength in AA2319 (Ref 21) and Ti-6Al-4V (Ref 42) or to improve the fatigue life (Ref 43).

\subsection{The Effect of Rolling on the Plastic Strain Distribution}

The effects of roller profile radius and rolling load on the plastic strain in longitudinal direction, as well as the equivalent plastic strain in Ti-6Al-4V, are shown in Fig. 6. Increasing the rolling load increases both the penetration depth as well as magnitude of plastic strain. The minimum penetration depth of plastic strain, which is $10 \%$ for Ti-6Al-4V (Ref 14) to obtain grain refinement, needs to be larger than the re-melting depth $(\sim 1.1 \mathrm{~mm})$ plus the new deposited layer height $(\sim 1.2 \mathrm{~mm})$, see Fig. 7 (Ref 19).

Figure 6 indicates that the rolling load of $20 \mathrm{kN}$ does not provide sufficient plastic strain at a depth of $\sim 3 \mathrm{~mm}$; instead, sufficient plastic strain is achieved down to $1 \mathrm{~mm}$ only; this is inadequate as this volume will be re-melted during the subsequent layer deposition. It is also evident that increasing rolling load to $45 \mathrm{kN}$ and $70 \mathrm{kN}$ increases the plastic strain from 4 to $11 \%$ at the target depth of $3 \mathrm{~mm}$.

Table 2 Process parameters (rolling loads and roller profile radii) and as-clamped residual stresses as considered in this paper during the rolling of Ti-6Al-4V, S355JR steel and AA2319 walls

\begin{tabular}{|c|c|c|c|c|}
\hline & & Ti-6Al-4V & S355JR & AA2319 \\
\hline Initial longitudinal residual stress & $\sigma_{x x, \text { res }} / \mathrm{MPa}$ & 550 & 330 & 110 \\
\hline Minimum roller radius & $R_{\min } / \mathrm{mm}$ & 1.5 & 1.5 & 3 \\
\hline Maximum roller radius & $R_{\max } / \mathrm{mm}$ & 6 & 6 & 12 \\
\hline Minimum rolling load & $F_{\min } / \mathrm{kN}$ & 20 & 20 & 20 \\
\hline Maximum rolling load & $F_{\max } / \mathrm{kN}$ & 70 & 40 & 40 \\
\hline
\end{tabular}

\section{Rolling load $=70 \mathrm{kN}$}

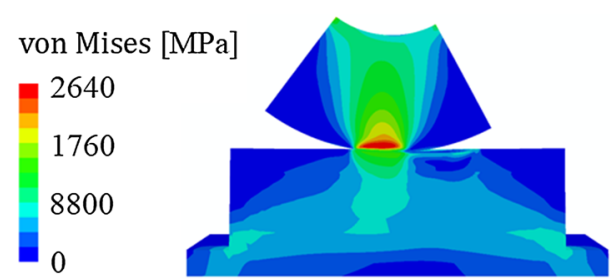

(a) Profile radius $=1.5 \mathrm{~mm}$

von $^{\text {Mises }}$ max $=2742 \mathrm{MPa}$

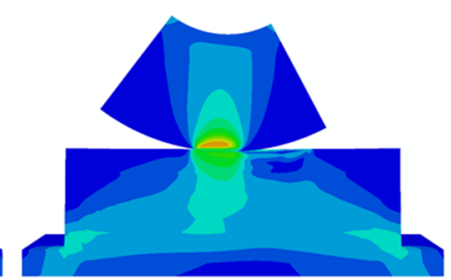

(b) Profile radius $=3 \mathrm{~mm}$ von Mises $_{\max }=2188 \mathrm{MPa}$

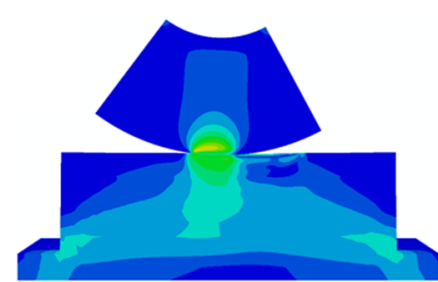

(c) Profile radius $=6 \mathrm{~mm}$ von Mises $_{\text {max }}=1926 \mathrm{MPa}$

Fig. 3 Equivalent von Mises stresses in roller as well as in Ti-6Al-4V specimen (wall and substrate) during rolling with rolling load of $70 \mathrm{kN}$ for three different roller profile radii 

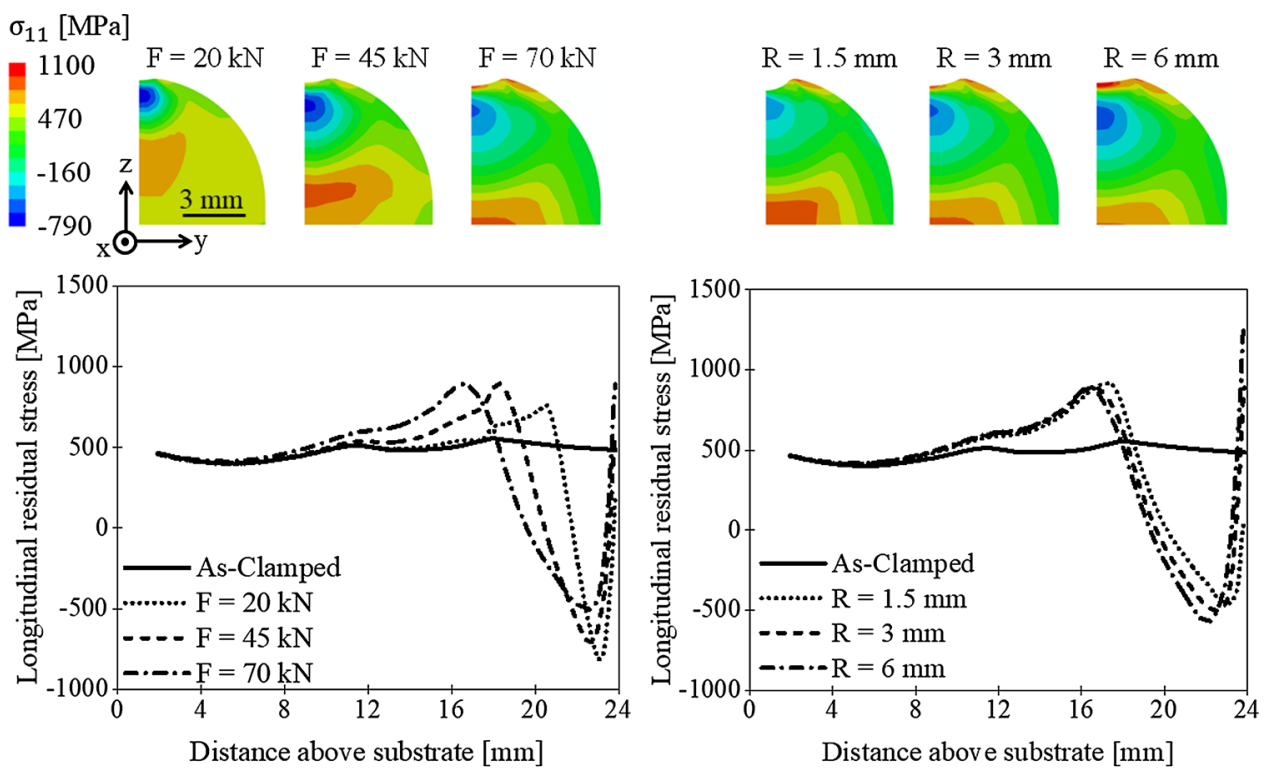

(a) Roller profile radius $=3 \mathrm{~mm}$

(b) Rolling load $=70 \mathrm{kN}$

Fig. 4 Longitudinal residual stresses in Ti-6Al-4V after rolling for different rolling loads and rolling radii: (a) roller with 3-mm profile radius at three different rolling loads; (b) constant rolling load of $70 \mathrm{kN}$ for different roller profile radii

Instead, reducing the roller profile radius increases the plastic strain to within $2 \mathrm{~mm}$ from the surface. In the relevant region at greater depth, however, the level of plastic strain does not depend on the profile at all, see Fig. 6(b). It is therefore advisable to use larger roller profiles, instead of smaller ones, which also have a higher risk of failure and would only induce the same strain at the target depth.

The required minimum plastic strain (Ref 8,15$)$, as well as the required penetration depth ( $\operatorname{Ref} 8,44)$, depends on the particular material as well as the specific application. In the current case, both are different for steel and aluminum to receive microstructural refinement and pore elimination, respectively. The resulting equivalent plastic strain distributions for S355JR steel and AA2319 after rolling with a profile radius of $3 \mathrm{~mm}$ at three different rolling loads are shown in Fig. 8. The trends are comparable for both metals and for Ti-6Al-4V. Considering porosity as one of the challenges in WAAM of AA2319 (Ref 1), the plastic strain required to eliminate porosity is $>40 \%$ (Ref 15$)$; the depth at which such strain has to be achieved needs to be as large as the re-melting depth $(\sim 3.5 \mathrm{~mm})$ plus the layer height $(\sim 2.5 \mathrm{~mm})$ (Ref 44$)$. Figure 8(b) indicates that the rolling of WAAM AA2319 using a profiled roller does not result in the required plastic strain at the depth of $6 \mathrm{~mm}$. However, Gu et al. (Ref 15), who used a flat roller and a rolling load of $45 \mathrm{kN}$, produced enough deformation to eliminate porosity. Unfortunately, the option of using a rolling load higher than $40 \mathrm{kN}$ with a profiled roller is not feasible, as it would result in excessive strain at the surface and related material failure.

In summary, larger profiles allow the use of higher forces, which is actually the only parameter that determines the penetration depth of plastic deformation. The required penetration depth for the plastic strain can be reduced by reducing the re-melting depth or the layer height, the latter being undesirable due to a possible reduction in deposition rate. Certain power sources, such as plasma transferred arc or tungsten inert gas, for example, Ref 45, 46, 47 can have less re- melting (compared to gas metal arc power sources) at similar deposition rates, making them more compatible for inter-pass rolling of single passes (Ref 44, 46, 48). Other DED systems with lower layer height and less re-melting, such as laser + powder or laser + wire deposition (Ref 43, 42, 49), might also be very suitable for inter-pass rolling.

\subsection{Design Curves for Strain Induction}

The effect of rolling load and roller profile radius was investigated on the equivalent plastic strain for all three materials in detail before. In this section, the results are summarized as design curves, providing guidelines based on the described numerical model, how one might chose rolling load and roller profile combinations for microstructural improvement or porosity elimination. In Fig. 9, the design curves of equivalent plastic strain for two different depths are shown for the three materials. These design curves are represented by Eq 2, where the coefficients are summarized in Table 3. In Fig. 10, the effect of roller profile radius on the equivalent plastic strain over the height of the wall is shown for the three materials. As discussed earlier, roller profile size does not affect the equivalent plastic strain at larger depth, but smaller profile radii produce higher plastic strain near the surface. When increasing the roller profile radius from 2 to $4 \mathrm{~mm}$, regardless of the material, the plastic strain near the top surface, i.e., at a depth of $1 \mathrm{~mm}$, decreases substantially, see Fig. 10. However, increasing the roller profile radius to $6 \mathrm{~mm}$ has an insignificant effect on the plastic strain near the surface. Therefore, it is concluded that rollers with even larger profiles have a similar effect on the plastic strain distribution as flat rollers. In Fig. 11, the effect of the rolling load on the equivalent plastic strain is shown for the three materials. For all materials, the rolling load has a similar effect on the plastic strain variation, i.e., increasing rolling load increases the value of plastic strain near the surface as well as the penetration depth of the plastic strain. It should be noted that for Ti-6Al-4V, 

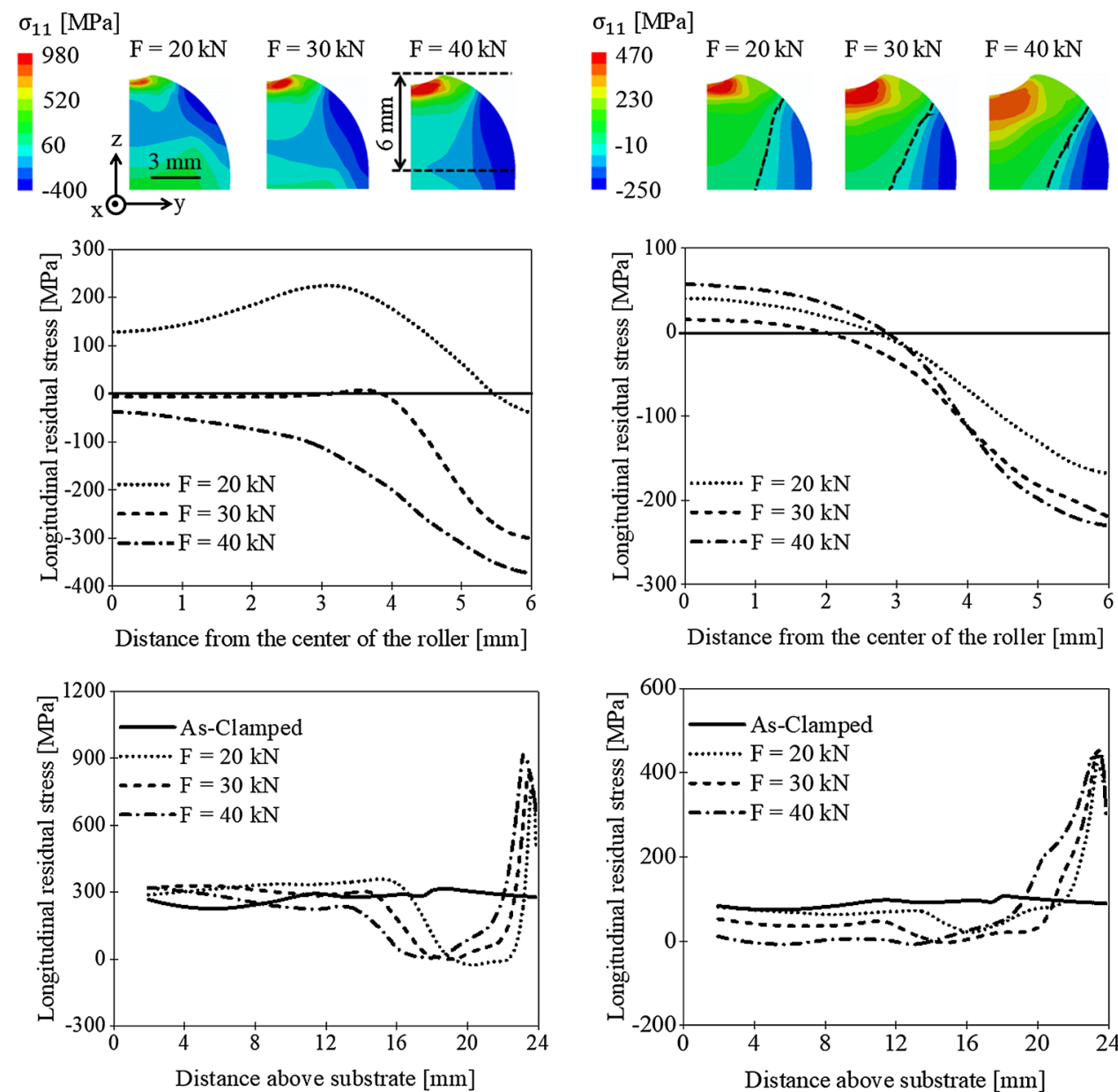

(a) S355JR steel

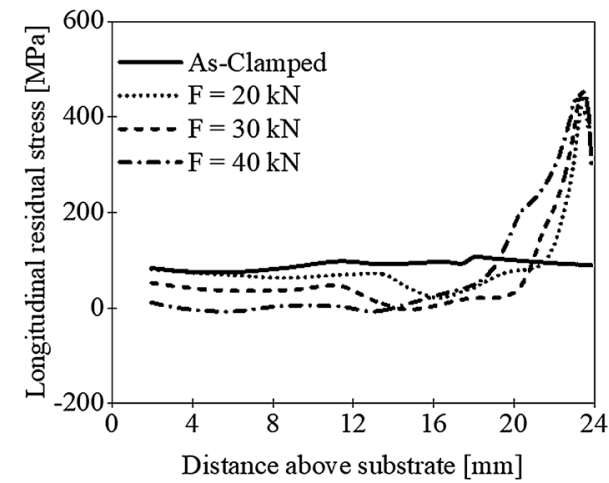

(b) AA2319

Fig. 5 Longitudinal residual stress distribution after rolling in S355JR steel and AA2319 wall with a 3-mm roller profile radius at 20, 30 and $40 \mathrm{kN}$ rolling load. The residual stresses (second row) are plotted at a depth of $6 \mathrm{~mm}$ along the width of the specimen (y-direction). The dashed line in the stress map in (b) indicates residual stresses of $0 \mathrm{MPa}$ within the structure

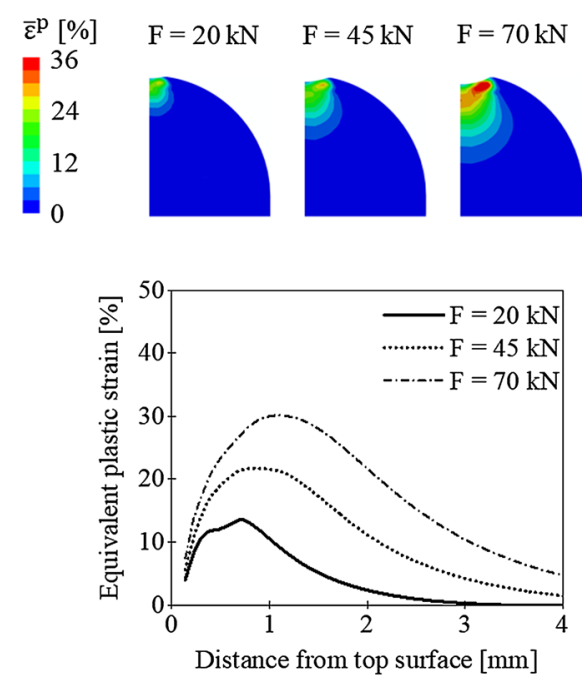

(a) Profile radius $=3 \mathrm{~mm}$
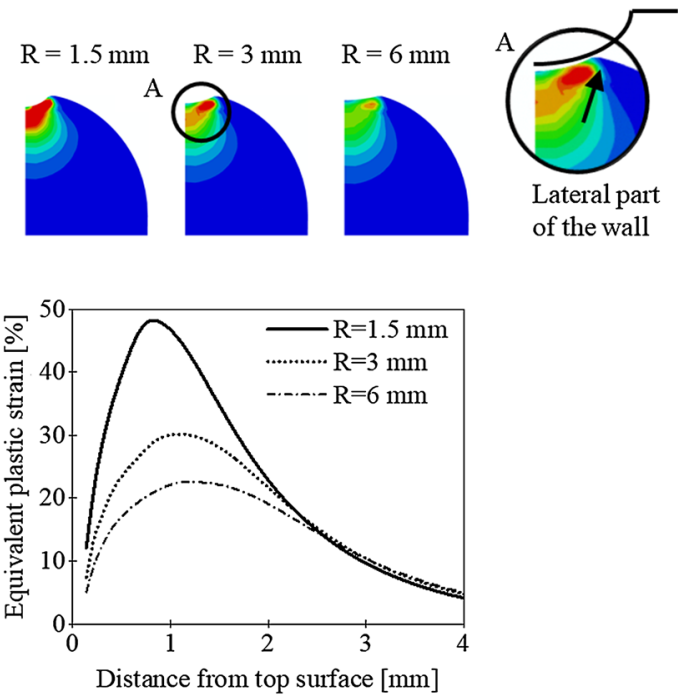

(b) Rolling load $=70 \mathrm{kN}$

Fig. 6 Equivalent plastic strain distribution in a Ti-6Al-4V wall after rolling. On the one hand, (a) a 3-mm profiled roller at different rolling loads, on the other hand, (b) a constant rolling load of $70 \mathrm{kN}$ for different roller profile radii are investigated 


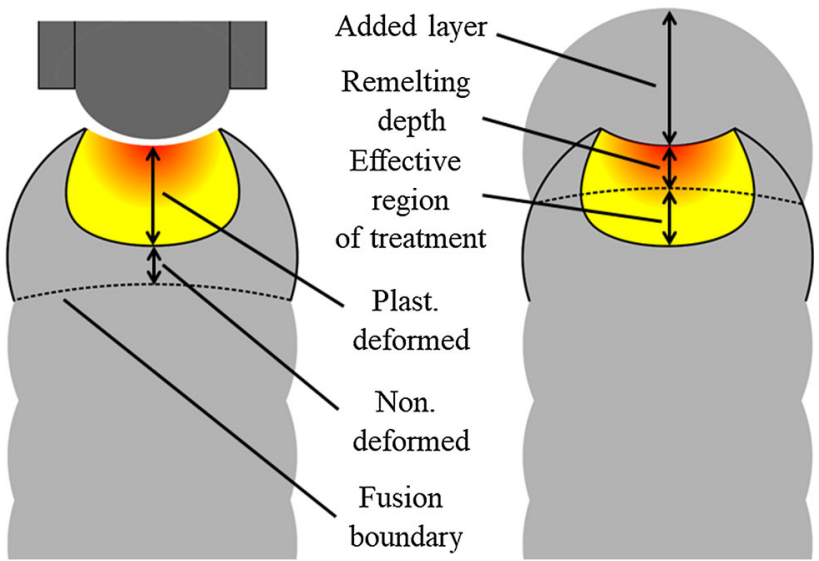

Fig. 7 Schematic of the re-melting effect during the deposition process. The minimum depth of the plastic strain to improve the microstructure needs to be larger than the re-melting depth plus the new deposited layer height increasing the rolling load from 30 to $50 \mathrm{kN}$ increases the plastic strain near the surface significantly, but increasing the rolling load from 50 to $70 \mathrm{kN}$ has less significant effect. Overall, these design curves might allow selection of suitable parameter combinations to obtain the required plastic strain to improve the microstructure, e.g., to refine the grain size in Ti-6Al-4V (Ref 14) and S355JR steel (Ref 8) or to eliminate the porosity in AA2319 (Ref 15, 16). Of course, the design curves are only valid for the three materials, showing the mechanical behavior as illustrated in Fig. 2, representing the basis of the simulation results.

\subsection{The Effect of Initial State of the Wall on the Residual Stresses and Plastic Strains}

In Fig. 12, the resultant longitudinal residual stresses after rolling for all three materials, with and without incorporating the initial residual stresses, are shown. It is obtained that independent of the initial residual stresses within the wall, the rolling load for the intended deformation depth is nearly identical, i.e., differences were less than $1 \%$. The equivalent
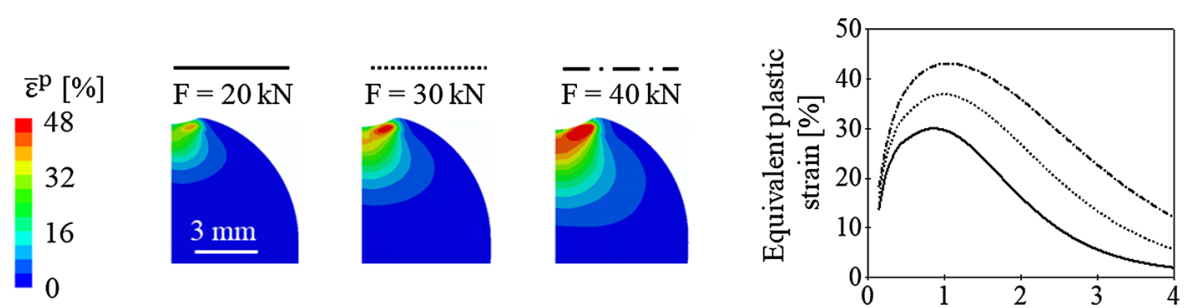

(a) S355JR steel

Distance from top surface $[\mathrm{mm}]$
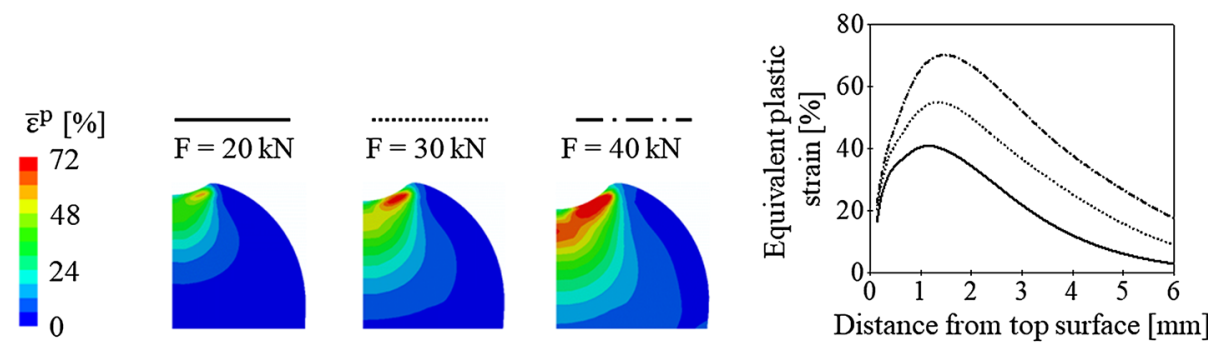

(b) AA2319

Fig. 8 Equivalent plastic strain after rolling of S355JR steel (a) and AA2319 (b) wall with 3-mm roller profile radius and 20, 30 and $40 \mathrm{kN}$ rolling load

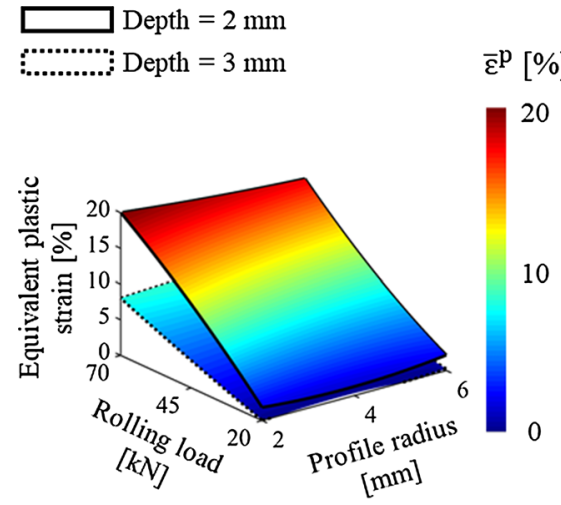

(a) Ti-6Al-4V

20
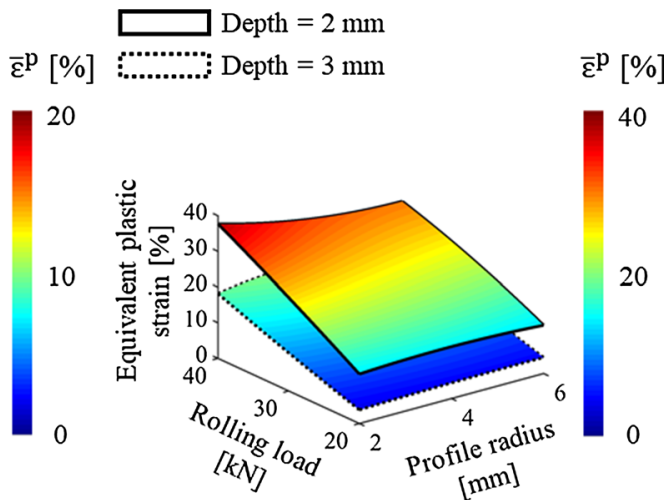

(b) S355JR steel

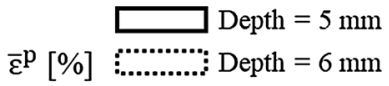

$\bar{\varepsilon}^{\mathrm{p}}[\%]$

40

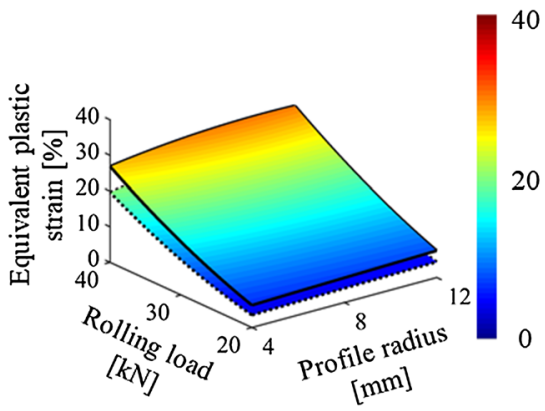

(c) AA2319

Fig. 9 Design curves for equivalent plastic strain as function of rolling load and roller profile radius for (a) Ti-6Al-4V, (b) S355JR steel and (c) AA2319 walls at two different depths are shown 
Table 3 Coefficients of regression model (Eq 2) representing plastic strain at different depths for Ti-6Al-4V, S355JR steel and AA2319

\begin{tabular}{lcllcccc}
\hline & & \multicolumn{5}{c}{ Coefficients } \\
\cline { 3 - 7 } Material & Depth, $\mathbf{m m}$ & \multicolumn{1}{c}{$\boldsymbol{a}_{\mathbf{1}}$} & $\boldsymbol{a}_{\mathbf{2}}$ & $\boldsymbol{a}_{\mathbf{3}}$ & $\boldsymbol{a}_{\mathbf{4}}$ & $\boldsymbol{a}_{\mathbf{5}}$ & $\boldsymbol{a}_{\mathbf{6}}$ \\
\hline \multirow{2}{*}{ Ti-6Al-4V } & 2 & -0.0032 & 0.2 & 0.65 & -0.185 & -0.082 & -7.7 \\
& 3 & 0 & 0.0779 & 0.2 & -0.01 & -0.037 & -2.987 \\
S355JR steel & 2 & 0.005 & -0.436 & 1.47 & 4.17 & -0.0114 & -20 \\
AA2319 & 3 & -0.0032 & 0.0849 & 0.6646 & 0.3617 & -0.0639 & -9.17 \\
& 5 & 0.0136 & 0.0214 & -0.0014 & -0.4055 & 0.0113 & 0.1108 \\
& 6 & 0.0134 & 0.019 & -0.2216 & -0.2981 & 0 & 1.9322 \\
\hline
\end{tabular}

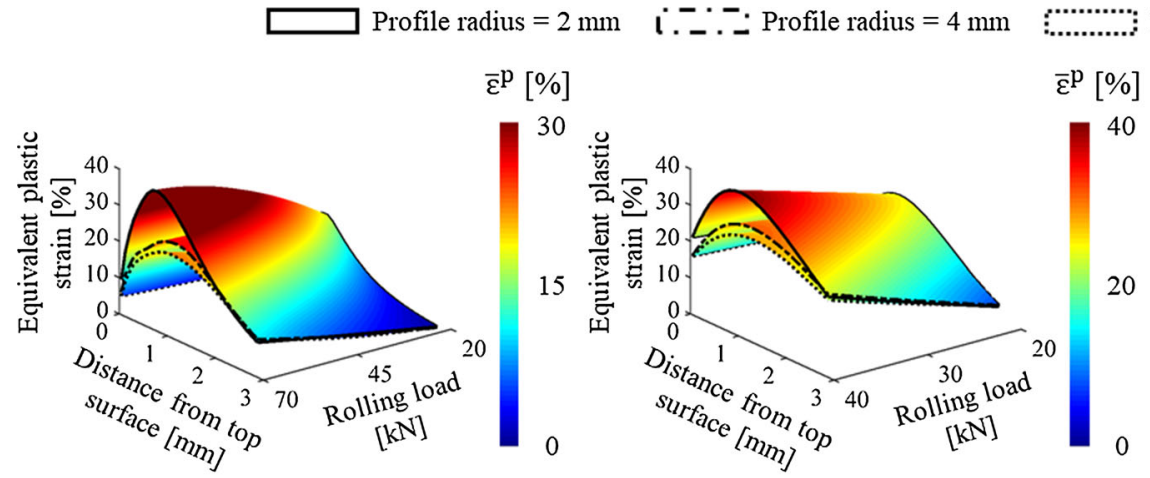

(a) Ti-6Al-4V

(b) S355JR steel Profile radius $=6 \mathrm{~mm}$

Fig. 10 Design curves for equivalent plastic strain as function of rolling load and depth at three different roller profile radii for (a) Ti-6Al-4V, (b) S355JR steel and (c) AA2319 walls are shown

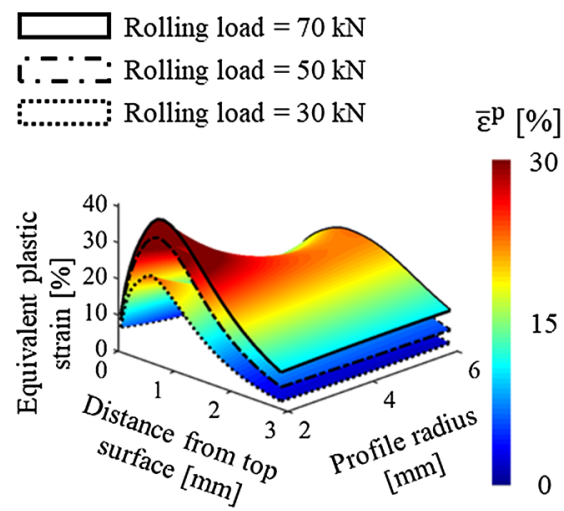

(a) Ti-6Al-4V
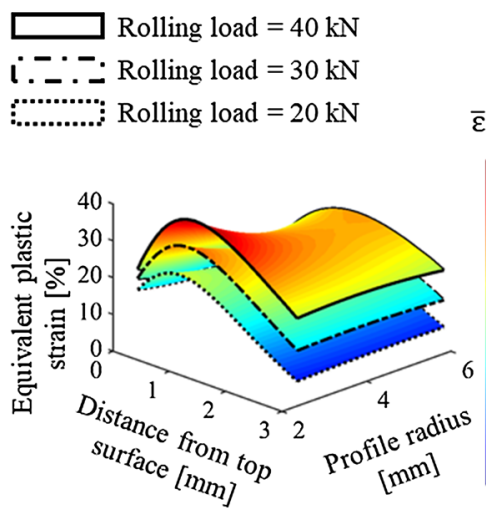

(b) S355JR steel

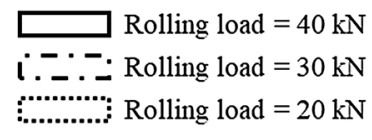

$\bar{\varepsilon}^{\mathrm{p}}[\%]$

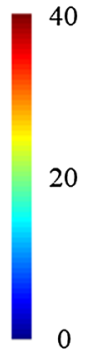

(c) AA2319

Fig. 11 Design curves for equivalent plastic strain as function of rolling profile radius and depth at three different rolling loads for (a) Ti-6Al4V, (b) S355JR steel and (c) AA2319 walls are shown. Rolling load increases the penetration depth and maximum value of the equivalent plastic strain

plastic strain distribution for all three materials is plotted in Fig. 13. The results show that the initial residual stresses have almost no effect on the equivalent plastic strain distribution of the wall as well. In order to understand the effect of the initial state of the wall on the resulting residual stress, rolling of a Ti$6 \mathrm{Al}-4 \mathrm{~V}$ wall at low rolling loads is investigated. Figure 14 shows the calculated error in the maximum longitudinal residual stress when neglecting the initial state. At an unrealistic low rolling load of $2 \mathrm{kN}$, an error of $60 \%$ is obtained. When increasing the rolling load, the effect of initial state of the wall on the resulting residual stresses decreases and at realistic rolling loads of more than $20 \mathrm{kN}$ becomes negligible so that the 


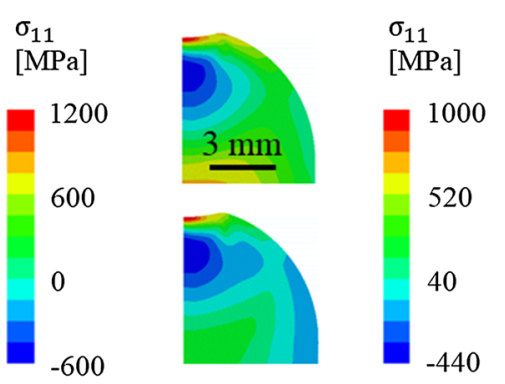

(a) $\mathrm{Ti}-6 \mathrm{Al}-4 \mathrm{~V}$
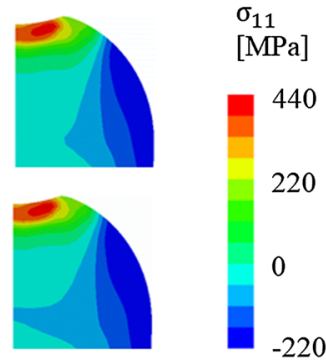

(b) S355IR steel $40 \mathrm{kN}$

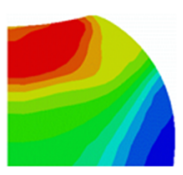

With

int. RS

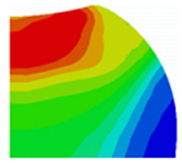

Without

int. RS

Fig. 12 Longitudinal residual stress distribution in (a) Ti-6Al-4V, (b) S355JR steel and (c) AA2319 walls with and without initial residual stresses. The chosen roller profile radius is $6 \mathrm{~mm}$ for Ti-6Al-4V and S355JR steel and $12 \mathrm{~mm}$ for AA2319

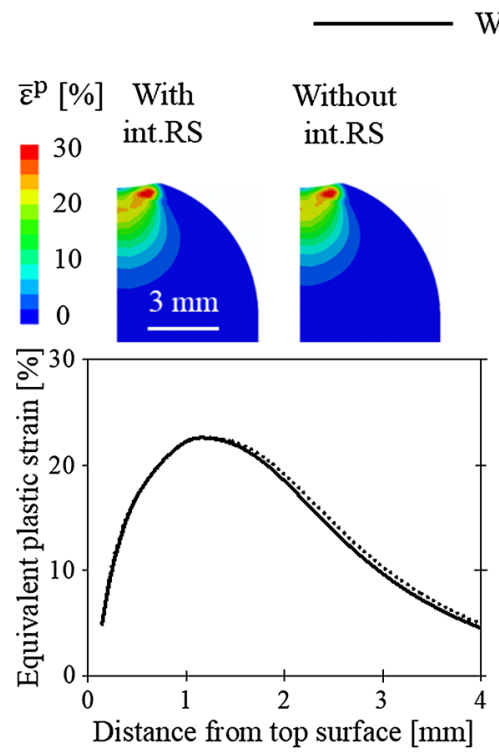

(a) Ti-6Al-4V
With int.RS

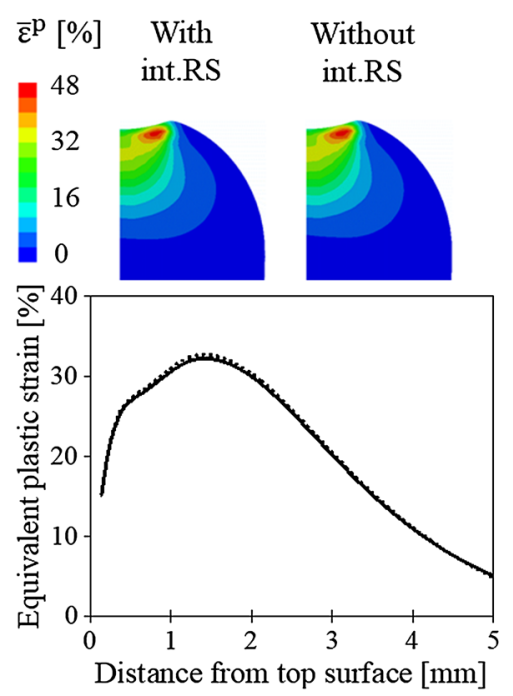

(b) S355JR steel
Without int.RS

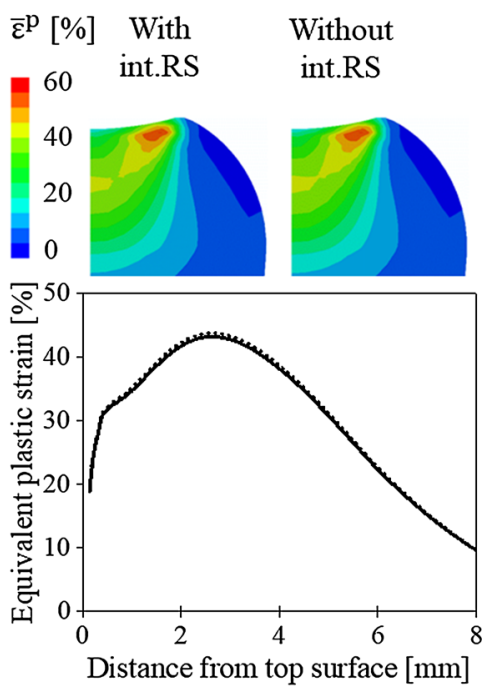

(c) AA2319

Fig. 13 Equivalent plastic strain distribution after rolling of (a) Ti-6Al-4V with $70 \mathrm{kN}$ rolling load and 6-mm roller profile radius, (b) S355JR steel with 40-kN rolling load and 6-mm roller profile radius, (c) AA2319 with 40-kN rolling load and 12-mm roller profile radius. The equivalent plastic strain is insensitive to the initial stress state

error in terms of the maximum longitudinal residual stresses tends to be zero, comparing the simulation results with and without initial residual stresses.

\section{Conclusion}

The finite element method was used to investigate the effect of rolling process parameters on wire + arc additively manufactured AA2319, S355JR steel and Ti-6Al-4V walls. The initial residual stresses were incorporated from the results of WAAM structures in the literature. The effects of rolling load, roller profile radius and initial residual stresses in the wall on the plastic strain induction and residual stress redistribution were investigated in detail. The following conclusions can be drawn from the presented results:

- As the rolling load increases, the depth of the compressive residual stresses increases. In general, as the load increases, the compressive residual stresses move from the core to the outer surfaces of the wall. In addition, higher rolling loads lead to a higher maximum equivalent plastic strain as well as a higher penetration depth of the equivalent plastic strain.

- The roller profile radius has an insignificant effect on the depth of the residual stress for all three materials. However, small profile radii nearly completely remove tensile residual stresses close to the surface. For smaller roller profile radii, the value of the equivalent plastic strain near the top surface of the wall increases, but there is no effect on the depth of the equivalent plastic strain.

- Initial residual stresses do not have a significant effect on the equivalent plastic strain distribution after rolling with realistic rolling loads of more than $20 \mathrm{kN}$.

- Profiled roller cannot produce the required plastic strain in the relatively large re-melting depth of AA2319 for realistic rolling loads. Thus, it is suggested to use a flat roller for rolling of AA2319 which enables use of higher rolling loads in order to reach the desired plastic strain greater than the re-melting depth. 


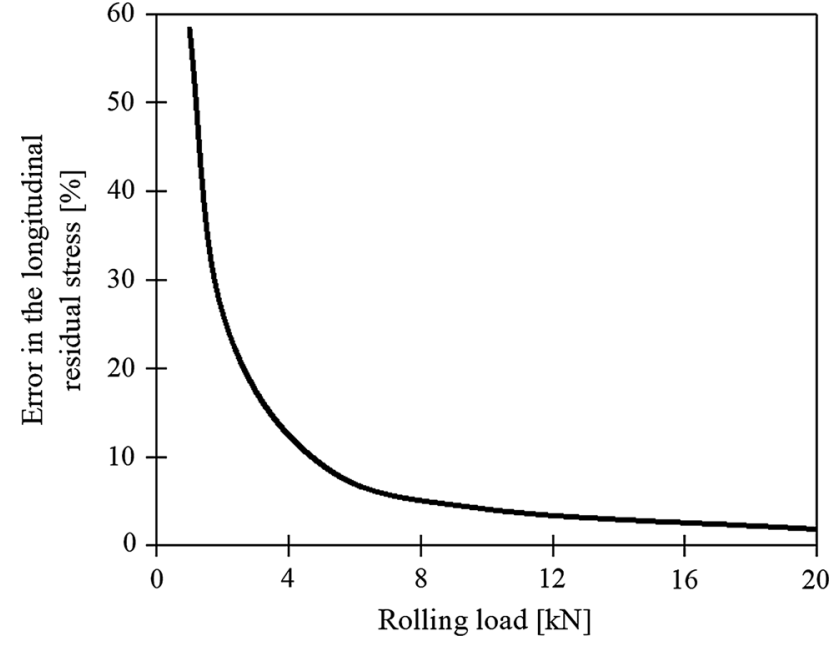

Fig. 14 Error in the maximum longitudinal residual stress for different rolling loads in Ti-6Al-4V walls, neglecting the initial residual stresses. The maximum stress in the wall is taken to calculate the error, $\left(\left(\sigma_{\max }^{\text {(with int.RS })}-\sigma_{\max }^{\text {(without int.RS })}\right)\right) /\left(\sigma_{\max }^{\text {(with int.RS })}\right)$. Increasing the rolling load to relevant loads, the effect of the initial state of the wall on the resulting residual stresses becomes negligible

- In general, it is suggested to choose the highest possible rolling load during the process and select the adequate profile radius to prevent a possible process breakdown of the roller or wall as well as to reach the required plastic strain in the desired depth.

\section{Acknowledgments}

This project has received funding from the European Union's Horizon 2020 research and innovation programme in the project LASIMM (Large Additive Subtractive Integrated Modular Machine) under Grant Agreement No. 723600 which is gratefully acknowledged. In addition, the authors thank Stefan Riekehr for conducting the compression tests to obtain the required material data for the simulation.
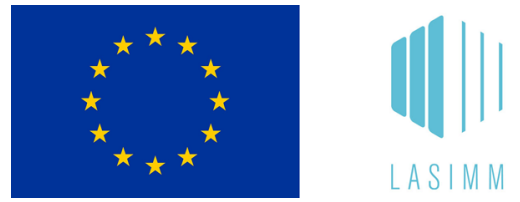

\section{Open Access}

This article is distributed under the terms of the Creative Commons Attribution 4.0 International License (http://creativecommons.org/ licenses/by/4.0/), which permits unrestricted use, distribution, and reproduction in any medium, provided you give appropriate credit to the original author(s) and the source, provide a link to the Creative Commons license, and indicate if changes were made.

\section{References}

1. S.W. Williams, F. Martina, A.C. Addison, J. Ding, G. Pardal, and P. Colegrove, Wire + Arc Additive Manufacturing, J. Mater. Sci. Tech- nol., 2015, 32, p 641-647. https://doi.org/10.1179/1743284715Y.000 0000073

2. C.R. Cunningham, J.M. Flynn, A. Shokrani, V. Dhokia, and S.T. Newman, Invited Review Article: Strategies and Processes for High Quality Wire Arc Additive Manufacturing, Addit. Manuf., 2018, 22, p 672-686. https://doi.org/10.1016/j.addma.2018.06.020

3. LASIMM Project (2018), http://www.lasimm.eu. Accessed 13 Aug 2018

4. J. Ding, P. Colegrove, J. Mehnen, S. Ganguly, P.M.S. Almeida, F. Wang, and S.W. Williams, Thermo-Mechanical Analysis of Wire and Arc Additive Layer Manufacturing Process on Large Multi-layer Parts, Comput. Mater. Sci., 2011, 50, p 3315-3322. https://doi.org/10.1016/ j.commatsci.2011.06.023

5. J. Zhang, X. Wang, S. Paddea, and X. Zhang, Fatigue Crack Propagation Behaviour in Wire + Arc Additive Manufactured Ti6Al-4V: Effects of Microstructure and Residual Stress, Mater. Des., 2016, 90, p 551-561. https://doi.org/10.1016/j.matdes.2015.10.141

6. J.R. Hönnige, P. Colegrove, S. Ganguly, E. Eimer, S. Kabra, and S.W. Williams, Control of Residual Stress and Distortion in Aluminium Wire + Arc Additive Manufacture with Rolling, Addit. Manuf., 2018, 22, p 775-783. https://doi.org/10.1016/j.addma.2018.06.015

7. J. Ding, P. Colegrove, J. Mehnen, S.W. Williams, F. Wang, and P.M.S. Almeida, A Computationally Efficient Finite Element Model of Wire and Arc Additive Manufacture, Int. J. Adv. Manuf. Technol., 2014, 70, p 227-236. https://doi.org/10.1007/s00170-013-5261-x

8. P. Colegrove, H.E. Coules, J. Fairman, F. Martina, T. Kashoob, H. Mamash, and L.D. Cozzolino, Microstructure and Residual Stress Improvement in Wire and Arc Additively Manufactured Parts Through High-Pressure Rolling, J. Mater. Process. Technol., 2013, 213, p 17821791. https://doi.org/10.1016/j.jmatprotec.2013.04.012

9. J.R. Hönnige, S.W. Williams, M.J. Roy, P. Colegrove, and S. Ganguly, Residual Stress Characterization and Control in the Additive Manufacture of Large Scale Metal Structures, in 10th International Conference on Residual Stress, Sydney (2016). https://doi.org/10.217 41/9781945291173-77

10. F. Martina, M.J. Roy, B.A. Szost, S. Terzi, P. Colegrove, S.W. Williams, P.J. Withers, J. Meyer, and M. Hofmann, Residual Stress of As-Deposited and Rolled Wire + Arc Additive Manufacturing Ti-6Al4V Components, Mater. Sci. Technol., 2016, 32, p 1439-1448. https://d oi.org/10.1080/02670836.2016.1142704

11. B.A. Szost, S. Terzi, F. Martina, D. Boisselier, A. Prytuliak, T. Pirling, M. Hofmann, and D.J. Jarvis, A Comparative Study of Additive Manufacturing Techniques: Residual Stress and Microstructural Analysis of CLAD and WAAM Printed Ti-6Al-4V Components, Mater. Des., 2016, 89, p 559-567. https://doi.org/10.1016/j.matdes.2015.09. 115

12. J.R. Hönnige, P. Colegrove, B. Ahmad, M.E. Fitzpatrick, S. Ganguly, T.L. Lee, and S.W. Williams, Residual Stress and Texture Control in Ti-6Al-4V Wire + Arc Additively Manufactured Intersections by Stress Relief and Rolling, Mater. Des., 2018, 150, p 193-205. http s://doi.org/10.1016/j.matdes.2018.03.065

13. F. Wang, S. Williams, P. Colegrove, and A.A. Antonysamy, Microstructure and Mechanical Properties of Wire and Arc Additive Manufactured Ti-6Al-4V, Metall. Mater. Trans. A, 2012, 44, p 968977. https://doi.org/10.1007/s11661-012-1444-6

14. J. Donoghue, A.A. Antonysamy, F. Martina, P. Colegrove, S.W. Williams, and P.B. Prangnell, The Effectiveness of Combining Rolling Deformation with Wire-Arc Additive Manufacture on $\beta$-Grain Refinement and Texture Modification in Ti-6Al-4V, Mater. Charact., 2016, 114, p 103-114. https://doi.org/10.1016/j.matchar.2016.02.001

15. J. Gu, J. Ding, S.W. Williams, H. Gu, P. Ma, and Y. Zhai, The Effect of Inter-layer Cold Working and Post-deposition Heat Treatment on Porosity in Additively Manufactured Aluminum Alloys, J. Mater. Process. Technol., 2016, 230, p 26-34. https://doi.org/10.1016/j.jma tprotec.2015.11.006

16. J. Gu, J. Ding, S.W. Williams, H. Gu, P. Ma, and Y. Zhai, The Strengthening Effect of Inter-Layer Cold Working and Post-deposition Heat Treatment on the Additively Manufactured Al-6.3Cu Alloy, Mater. Sci. Eng., A, 2016, 651, p 18-26. https://doi.org/10.1016/j.msea. 2015.10.101

17. P. Colegrove, J. Donoghue, F. Martina, J. Gu, P. Prangnell, and J.R. Hönnige, Application of Bulk Deformation Methods for Microstructural and Material Property Improvement and Residual Stress and Distortion Control in Additively Manufactured Components, Scr. 
Mater., 2017, 135, p 111-118. https://doi.org/10.1016/j.scriptamat.20 16.10 .031

18. Y. Lei, N.P. O'Dowd, and G.A. Webster, Fracture Mechanics Analysis of a Crack in a Residual Stress Field, Int. J. Fract., 2000, 106, p 195216. https://doi.org/10.1023/A:1026574400858

19. C. Charles and N. Jarvstrat, Finite element modelling of microstructure on GTAW metal deposition of Ti-6Al-4V alloy, in Proceedings of the 3rd International Conference on Mathematical Modeling and Information Technologies in Welding and Related Processes (2006), pp. 151-156

20. R. Pan, T. Pirling, J. Zheng, J. Lin, and C.M. Davies, Quantification of Thermal Residual Stresses Relaxation in AA7xxx Aluminium Alloy through Cold Rolling, J. Mater. Process. Technol., 2018, 264, p 454468. https://doi.org/10.1016/j.jmatprotec.2018.09.034

21. R. Sun, L. Li, Y. Zhu, W. Guo, P. Peng, B. Cong, J. Sun, Z. Che, B. Li, C. Guo, and L. Liu, Microstructure, Residual Stress and Tensile Properties Control of Wire-Arc Additive Manufactured 2319 Aluminum Alloy with Laser Shock Peening, J. Alloys Compd., 2018, 747, p 255-265. https://doi.org/10.1016/j.jallcom.2018.02.353

22. A.M. Thompson, M. Fresini, J. Dos Santos, J. Hedgegard, U. Dithey, I.M. Richardson, and D. Yapp, Improving the Competitiveness of the European Steel Fabrication Industry Using Synchronised Tandem Wire Welding Technology, vol. 80224 (2008). https://doi.org/10.2777/1085

23. B.E. Carroll, T.A. Palmer, and A.M. Beese, Anisotropic Tensile Behavior of Ti-6Al-4V Components Fabricated with Directed Energy Deposition Additive Manufacturing, Acta Mater., 2015, 87, p 309-320. https://doi.org/10.1016/j.actamat.2014.12.054

24. Y. Chen, S. Sun, and C. Ji, Analysis of Aluminum Sheets with Multiple Sites Damage Based on Fatigue Tests and DIC Technique, Int. J. Fatigue, 2018, 109, p 37-48. https://doi.org/10.1016/j.ijfatigue.2017.12.008

25. D. Castagnetti, A. Spaggiari, and E. Dragoni, Assessment of the Cohesive Contact Method for the Analysis of Thin-Walled Bonded Structures, Int. J. Adhes. Adhes., 2012, 37, p 112-120. https://doi.org/ 10.1016/j.ijadhadh.2012.01.012

26. X. Wang, X. Gong, and K. Chou, Scanning Speed Effect on Mechanical Properties of Ti6Al-4V Alloy Processed by Electron Beam Additive Manufacturing, in 43rd Proceedings of the North American Manufacturing Research Institution (2015), pp. 287-295. https://doi. org/10.1016/j.promfg.2015.09.026

27. J. Mehnen, J. Ding, H. Lockett, and P. Kazanas, Design Study for Wire and Arc Additive Manufacture, Int. J. Prod. Dev., 2014, 19, p 2-20. https://doi.org/10.1504/IJPD.2014.060028

28. F. Montevecchi, G. Venturini, A. Scippa, and G. Campatelli, Finite Element Modelling of Wire-Arc-Additive-Manufacturing Process, Procedia CIRP, 2016, 55, p 109-114. https://doi.org/10.1016/j.procir. 2016.08.024

29. X. Bai, H. Zhang, and G. Wang, Modeling of the Moving Induction Heating Used as Secondary Heat Source in Weld-Based Additive Manufacturing, Int. J. Adv. Manuf. Technol., 2015, 77, p 717-727. https://doi.org/10.1007/s00170-014-6475-2

30. F. Shu, Y. Lv, Y. Liu, F. Xu, Z. Sun, P. He, and B. Xu, Residual Stress Modeling of Narrow Gap Welded Joint of Aluminum Alloy by Cold Metal Transferring Procedure, Constr. Build. Mater., 2014, 54, p 224 235. https://doi.org/10.1016/j.conbuildmat.2013.12.056

31. A.M. Korsunsky, The Modelling of Residual Stresses due to Surface Peening Using Eigenstrain Distributions, J. Strain Anal. Eng. Des., 2005, 40(2005), p 817-824. https://doi.org/10.1243/030932405X30984

32. A.M. Korsunsky, Residual Elastic Strain due to Laser Shock Peening: Modelling by Eigenstrain Distribution, J. Strain Anal. Eng. Des., 2006, 41, p 195-204. https://doi.org/10.1243/03093247JSA141

33. T.S. Jun and A.M. Korsunsky, Evaluation of Residual Stresses and Strains Using the Eigenstrain Reconstruction Method, Int. J. Solids Struct., 2010, 47, p 1678-1686. https://doi.org/10.1016/j.ijsolstr.2010. 03.002

34. B. Klusemann, R. Denzer, and B. Svendsen, Microstructure Based Modeling of Residual Stresses in WC-12Co-Sprayed Coatings, J. Therm. Spray Technol., 2012, 21, p 96-107. https://doi.org/10.1007/ s11666-011-9690-5
35. T. Mukherjee, W. Zhang, and T. DebRoy, An Improved Prediction of Residual Stresses and Distortion in Additive Manufacturing, Comput. Mater. Sci., 2017, 126, p 360-372. https://doi.org/10.1016/j.commatsc i. 2016.10 .003

36. B. AlMangour, D. Grzesiak, and J.M. Yang, Nanocrystalline TiCReinforced H13 Steel Matrix Nanocomposites Fabricated by Selective Laser Melting, Mater. Des., 2016, 96, p 150-161. https://doi.org/10. 1016/j.matdes.2016.02.022

37. L.D. Cozzolino, H.E. Coules, P. Colegrove, and S. Wen, Investigation of Post-weld Rolling Methods to Reduce Residual Stress and Distortion, J. Mater. Process. Technol., 2017, 247, p 243-256. http s://doi.org/10.1016/j.jmatprotec.2017.04.018

38. J. Foehrenbach, V. Hardenacke, and M. Farajian, High Frequency Mechanical Impact Treatment (HFMI) for the Fatigue Improvement: Numerical and Experimental Investigations to Describe the Condition in the Surface Layer, Weld. World, 2016, 60, p 749-755. https://doi.org/ 10.1007/s40194-016-0338-4

39. F. Martina, P. Colegrove, S.W. Williams, and J. Meyer, Microstructure of Interpass Rolled Wire + Arc Additive Manufacturing Ti-6Al-4V Components, Metall. Mater. Trans. A, 2015, 46, p 6103-6118. https://d oi.org/10.1007/s11661-015-3172-1

40. J.R. Hönnige, Thermo-mechanical Control of Residual Stress, Distortion and Microstructure in Wire + Arc Additively Manufactured Ti-6Al$4 V, \mathrm{PhD}$ Thesis, Cranfield University, Cranfield, 2018

41. A.R. McAndrew, M.A. Rosales, P. Colegrove, J.R. Hönnige, A. Ho, R. Fayolle, K. Eyitayo, I. Stana, P. Sukrongpang, A. Crochemore, and Z. Pinter, Interpass Rolling of Ti-6Al-4V Wire + Arc Additively Manufactured Features for Microstructural Refinement, Addit. Manuf., 2018, 21, p 340-349. https://doi.org/10.1016/j.addma.2018.03.006

42. W. Guo, R. Sun, B. Song, Y. Zhu, F. Li, Z. Che, B. Li, C. Guo, L. Liu, and P. Peng, Laser Shock Peening of Laser Additive Manufactured Ti6Al4V Titanium Alloy, Surf. Coat. Technol., 2018, 349, p 503-510. https://doi.org/10.1016/j.surfcoat.2018.06.020

43. S. Luo, W. He, K. Chen, X. Nie, L. Zhou, and Y. Li, Regain the Fatigue Strength of laser Additive Manufactured Ti Alloy Via Laser Shock Peening, J. Alloys Compd., 2018, 750, p 625-635. https://doi.org/10. 1016/j.jallcom.2018.04.029

44. B. Cong, J. Ding, and S.W. Williams, Effect of Arc Mode in Cold Metal Transfer Process on Porosity of Additively Manufactured Al- $6.3 \% \mathrm{Cu}$ Alloy, Int. J. Adv. Manuf. Technol., 2015, 76, p 1593-1606. https://doi.org/ 10.1007/s00170-014-6346-x

45. F. Martina, J. Mehnen, S.W. Williams, P.A. Colegrove, and F. Wang, Investigation of the Benefits of Plasma Deposition for the Additive Layer Manufacture of Ti-6Al-4V, J. Mater. Process. Technol., 2012, 212, p 1377-1386. https://doi.org/10.1016/j.jmatprotec.2012.02.002

46. X. Xu, S. Ganguly, J. Ding, C.E. Seow, and S.W. Williams, Enhancing Mechanical Properties of Wire + Arc Additively Manufactured INCONEL 718 Superalloy Through In-Process Thermomechanical Processing, Mater. Des., 2018, 160, p 1042-1051. https://doi.org/10. 1016/j.matdes.2018.10.038

47. J.R. Hönnige, P.A. Colegrove, and S.W. Williams, Improvement of Microstructure and Mechanical Properties of Wire + Arc Additively Manufactured Ti-6Al-4V with Machine Hammer Peening, Procedia Eng., 2017, 216, p 8-17. https://doi.org/10.1016/j.proeng.2018.02.083

48. P.M.S. Almeida, Innovative Process Model of Ti-6Al-4V Additive Layer Manufacturing Using Cold Metal Transfer (CMT), in Proccedings 21st Annual International Solid Freeform Fabrication Symposium (2010)

49. M. Froend, S. Riekehr, N. Kashaev, B. Klusemann, and J. Enz, Process Development for Wire-Based Laser Metal Deposition of 5087 Aluminium Alloy by Using Fibre Laser, J. Manuf. Process., 2018, 34, p 721-732. https://doi.org/10.1016/j.jmapro.2018.06.033

Publisher's Note Springer Nature remains neutral with regard to jurisdictional claims in published maps and institutional affiliations. 